\title{
Mesleki Eğitimin Sorunları Bağlamında İmam Hatip Liselerinde Meslek Dersleri ve Öğretimi Üzerine Bir Analiz
}

\author{
${ }^{1}$ Davut KARAMAN
}

\section{ÖZET}

Bu tebliğg İmam hatip okullarında meslek dersleri ve öğretimi ile ilgili sorunları öğrenciler üzerine yapılan araştırmalarla incelenmesini amaçlamaktadır. Tebliğin oluşturulmasında literatür taraması tercih edilmiştir. İmam hatip okullarının toplumun akademik anlamda ve din öğretimi ile ilgili ilgi, istek ve beklentilerine cevap verme oranı ile bağlantılı olarak okul ve öğrenci sayılarında artış yaşandığı görülmektedir. Proje okul uygulamaları sayesinde imam hatip okullarındaki akademik başarının artması ile birlikte öğrencilerin manevi yönünü destekleyen meslek dersleri ve öğretiminin durumu hakkında çalışmaların yapılması önem arz etmektedir. Bu amaçla hazırlanan bu tebliğde meslek dersleri ve öğretimine ilişkin imam hatip lisesi öğrencileri üzerine yapılan araştırmalarda; öğrencilerin meslek derslerine olan ilgilerinin zayıf olduğu, meslek derslerinin işleyiş yönteminin öğrencilerin ilgisini çekmediği, meslek dersleri öğretmenlerinin rol model olma konusundaki zayıflığı ve meslek derslerinin sayısının ve ders saatlerinin ders programlarında azaltılması gerektiği gibi hususların çoğunlukla öne çıktığı görülmektedir.

Anahtar Kelimeler: İmam hatip lisesi, öğrenci, meslek dersleri ve öğretimi, sorunlar

\section{An Analysis of Vocational Courses And Teaching In Imam Hatip High Schools In The Context Of The Problems Of Vocational Education}

\begin{abstract}
This statement aims to examine the problems related to vocational courses and teaching in Imam hatip schools with research conducted on students. Literature review was preferred in the creation of the communique. It is seen that there is an increase in the number of schools and students in connection with the rate at which Imam hatip schools respond to the interests, desires and expectations of society in an academic sense and related to the teaching of religion. Thanks to the project school applications, it is important to carry out studies on the status of vocational courses and teaching that support the spiritual aspect of students, as well as increasing academic success in imam hatip schools. For this purpose, in the research conducted on imam hatip high school students related to the vocational courses and teaching of this bde prepared for this purpose,; it is seen that students ' interest in vocational courses is weak, the method of functioning of vocational courses is not of interest to students, the weakness of vocational courses teachers in being role models and the number of vocational courses and class hours should be reduced in the curriculum, as well as issues such as mostly stand out.
\end{abstract}

Keywords: Imam Hatip High School, Students, Vocational Courses and Teaching, Problems

\section{GíRiş}

İmam hatip okulları kuruluş itibariyle hemen hemen Cumhuriyetle yaşı köklü bir eğitim kurumudur. 1924 yılından beri örgün eğitim yapan imam hatip okulları, Tevhid-i Tedrisat Kanunu'nun 4. Maddesinin amir hükmü doğrultusunda din hizmetleri için gerekli olan din görevlilerinin yetiştirilmesi amaciyla kurulmuştur (Zengin, 2017,41). Kuruluşunun akabinde yaklaşık yirmi yıl kapalı kalan bu okullar 1951 yılında imam hatip okulu adıyla tekrar Türk eğitim sistemindeki yerini almıştır (Öcal, 1999, 204). 1973 yılında bugünkü adını alan imam hatip liseleri hem dinin ifası vazifesiyle önemli bir rolü üstlenerek imam hatiplik, müezzin kayyımlık ve Kur'an Kursu öğreticiliği statülerinde mesleğe hem de yükseköğrenime öğrenci hazırlayan bir kurum olarak öğretime devam etmektedir. Özellikle din eğitim ve öğretimi noktasındaki misyonu sebebiyle zaman içinde toplumun teveccühüne mazhar olmuştur. Bugün gelinen noktada imam hatip okullarında hem nitelik hem de

\footnotetext{
${ }^{1}$ Sorumlu Yazar: Dr., Milli Eğitim Bakanlığı, davutkaraman54@gmail.com
} 
nicel anlamda artış söz konusudur. Nicel olarak artışı son on yılın istatistiklerinde görmek mümkündür.

Tablo 1: 2011-2021 Y111 İmam Hatip Okullarındaki Sayısal Durum

\begin{tabular}{|c|c|c|c|c|c|}
\hline & \multicolumn{2}{|c|}{ Orta Kısım } & \multicolumn{2}{|c|}{ Lise Kısmı } & \\
\hline Öğretim & Okul & Öğrenci & Okul & Öğrenci & Toplam \\
\hline Yol1 & Sayıs1 & Say1s1 & Say1s1 & Say1s1 & Öğrenci \\
\hline 2011-2012 & - & - & 537 & 268,245 & 268,245 \\
\hline $2012-2013$ & 1099 & 94,467 & 708 & 380,771 & 475,238 \\
\hline 2013-2014 & 1368 & 209,194 & 851 & 493,501 & 692,695 \\
\hline 2014-2015 & 1597 & 385,830 & 1017 & 546,443 & 932,273 \\
\hline $2015-2016$ & 1961 & 524,295 & 1149 & 555,870 & $1,080,165$ \\
\hline 2016-2017 & 2971 & 651,954 & 1452 & 506,516 & $1,158,470$ \\
\hline $2017-2018$ & 3286 & 723,108 & 1604 & 514,806 & $1,237,914$ \\
\hline 2018-2019 & 3394 & 761,785 & 1623 & 498,002 & $1,259,787$ \\
\hline 2019-2020 & 3437 & 777,439 & 1650 & 502,847 & $1,280,286$ \\
\hline $2020-2021$ & 3427 & 714,297 & 1672 & 568,715 & $1.283,012$ \\
\hline
\end{tabular}

Tablo 1'de görüldüğü gibi, 2020-2021 öğretim yllında 3427 imam hatip ortaokulunda (İHO), 714,297 öğrenci; 1672 Anadolu İmam Hatip Lisesinde (AİHL) ise 568,715 öğrenci kayıtl1 bulunmaktadır. Türk eğitim sistemindeki okullaşma ve öğrenci sayıları kapsamında değerlendirildiğinde 19,025 ortaokuldan \%18,01'i imam hatip ortaokulundan ve tüm ortaokul öğrencilerinin \%13,70'i İmam hatip ortaokulu öğrencilerinden; ortaöğretim içerisindeki 12,972 ortaöğretim kurumundan \%12,88'i AİHL ve tüm ortaöğretim öğrencilerinin \%9,00'u ise AİHL öğrencilerinden oluşmaktadır (MEB, 2021, 132).

İHL dişındaki mesleki ve teknik liselerin genel ortaöğretim içerisindeki oranı ise 2020-2021 eğitim-öğretim y1lı itibariyle Tablo 3'te belirtilmiştir.

Tablo 3: 2020-2021 Y1l1 Mesleki ve Teknik Liselerindeki Sayısal Durum

\begin{tabular}{ccccc}
\hline & \multicolumn{2}{c}{ Genel Ortaöğretim } & \multicolumn{2}{c}{ Mesleki ve Teknik Anadolu Lisesi } \\
\hline Öğretim Y111 & Okul Sayıs1 & Öğrenci Sayıs1 & Okul Sayıs1 & Öğrenci Sayıs1 \\
\hline $2020-2021$ & 129,72 & $6.318,602$ & 4027 & 1604,276 \\
\hline
\end{tabular}

Tablo 3'te görüldüğü gibi, 2020-2021 öğretim yılında 4027 mesleki ve teknik anadolu lisesinde, 1.604,276 öğrenci kayıtlı bulunmaktadır. Türk eğitim sistemindeki okullaşma ve öğrenci sayıları kapsamında değerlendirildiğinde 12,972 genel ortaöğretim kurumundan \%31,04'ü mesleki ve teknik anadolu lisesinden ve tüm ortaöğretim öğrencilerinin $\% 25,38$ 'i ise mesleki ve teknik anadolu lisesi öğrencilerinden oluşmaktadır (MEB, 2021, 132).

Tablo 3 ve Tablo 4'teki veriler incelendiğinde hem imam hatip liseleri hem de mesleki ve teknik anadolu liselerinin genel ortaöğretim içerisindeki okullaşma oranı $\% 43,92$; öğrenci oranı ise \%34,38'dir. Bu bağlamda Türk eğitim sistemi içerisinde ortaöğretim düzeyinde öğrenim gören her üç öğrenciden biri meslek lisesi statüsünde öğrenim gören öğrencilerden oluşmaktadır. Bu durum meslek liselerindeki eğitim öğretim sürecinin önemini daha da arttırmaktadır. Yükseköğrenimde özellikle uygulama boyutu olan alanlardaki ihtiyacı karşılamak için aday olan öğrencilerin 3 'te biri meslek liseli öğrencilerden oluşmaktadır. Bu nedenle meslek liselerindeki eğitimin tüm boyutlarıyla ele alınması önem arz etmektedir. Bu bildiri de sadece meslek liselerinin yaklaşık üçte birini oluşturan imam hatip liselerindeki meslek dersleri ve öğretimi üzerine yapılmış çalışmalara odaklanılmıştır.

2016 yılından itibaren Türk eğitim sistemi içerisinde ortaöğretim kurumlarında kaliteyi arttırmak için yeni bir uygulama modeli olarak "Proje okul" statüsünde okullar oluşturulmaya 
başlanmıştır. Ortaöğretim kurumları içerisinde fen ve sosyal bilimler liselerinin tamamı, anadolu liselerinin bazıları ve meslek liselerinin bazı bölümleri proje okul statüsünde öğrenci alarak eğitim öğretim sürecini yürütmektedir. İmam hatip liseleri içerisinde de "Proje" Anadolu İmam Hatip Liseleri ihdas edilerek gerek ortaokul gerekse imam hatip ortaokullarında okuyan ögrencilerin tercih edebileceği ortaöğretim düzeyinde nitelikli okullar oluşturulmaya başlanmıştır. Proje okul uygulaması ve program çeşitliliği ile İHL'lerde eğitim kalitesine ilişkin yapılan çalışmaların bu okullara olan ilgiyi arttırdığı ifade edilebilir (Karaman, 2021, 46). Akademik anlamda başarılı öğrencilerin tercih ettiği proje okulların ve proje okul statüsü dışında adrese dayalı olarak ortaokul başarı puanına göre öğrenci alan İHL'lerin mesleki alanda öğrencilerini yetiştirme yeterliliği üzerine çalışmaların incelenmesi önem arz etmektedir. İHL öğrencilerinin 4-5 y1llık öğrenimleri süresince gördükleri meslek dersleri ve öğretimine ilişkin sorunlarının ve memnuniyet algılarının alanda yapılan çalışmaların taranarak ifade edilmesi bu araştırmanın amacını oluşturmaktadır. Bu bağlamda bu bildiride aşağıdaki soruya cevap aranmıştır.

- Araştırmalarda İHL öğrencilerinin meslek dersleri ve öğretimine ilişkin memnuniyetleri nasıldir?

Ders yükleri bağlamında imam hatip lisesi öğrencileri ders çeşitliliği açısından diğer liselerle birlikte görmek zorunda oldukları ortak dersler dışında 11 farklı ders adıyla toplamda 17 değişik derse girmek zorundadır. Bu dersler; Kur'an-1 Kerim-Öğretim Programı (9, 10, 11 ve 12. Sinıflar), Temel Dini Bilgiler-Öğretim Programı (9. Sınıf), Siyer-Öğretim Programı (10. Sınıf), Fıkıh-Öğretim Programı (11. Sınıf), Hadis-Öğretim Programı (11. Sınıf), Tefsir-Öğretim Programı (12. Sınıf), Karşılaştırmalı Dinler Tarihi-Öğretim Programı (12. Sınıf), İslam Tarihi-Öğretim Programı (12. Sınıf), Kelam-Öğretim Programı (12. Sınıf), Hitabet ve Mesleki Uygulama, Mesleki Arapça (9, 10, 11 ve 12 . Sınıflar) şeklinde11 farklı alanda ve toplamda 17 çeşitliliktedir. Bu kapsamda IHL'de uygulanan ders programları Tablo 2'de sunulmuştur.

Tablo 2: İmam Hatip Liselerinin Haftalık Ders Yükleri

\begin{tabular}{lcccc}
\hline & AïHL Haftalık Ders Çizelgesi & & \\
\hline Sınıf Düzeyi & $\mathbf{9}$ & $\mathbf{1 0}$ & $\mathbf{1 1}$ & $\mathbf{1 2}$ \\
\hline Ortak Dersler & 33 & 29 & 12 & 10 \\
\hline Meslek Dersleri & 6 & 11 & 12 & 12 \\
\hline Seçmeli Dersler & & & 16 & 18 \\
\hline Rehberlik & 1 & & & \\
\hline Toplam & $\mathbf{4 0}$ & $\mathbf{4 0}$ & $\mathbf{4 0}$ & $\mathbf{4 0}$ \\
\hline
\end{tabular}

Ortaöğretim bünyesinde öğretim yapan tüm kurumlar içerisinde meslek liseleri de bulunmaktadır. Meslek liseleri statüsünde de sayılan İHL'lerin meslek derslerini, diğer meslek liselerindeki öğrencilerin gördükleri derslerle karşılaştırdığımızda mesleki ve teknik anadolu lisesi öğrencilerinin farklı alanlarda girdiği ders çeşidinin 4 - 6 arasında değiştiği görülmektedir (MEB, 2018).

Bu dersler; Mesleki ve Teknik Anadolu Lisesi Gıda Teknolojisi alanında, Gıda Kalite Kontrol, Gıda İşleme dallarında 5 değişik alan ortak dersi, Hasta ve Yaşlı Bakım alanında 8 ortak ders, Hayvan Yetiştiriciliği ve Sağlığı alanı 6 ortak ders, Laboratuvar Hizmetleri Alanı 4 ortak ders, Sağlık hizmetleri alanı 9 ortak ders, Elektrik-Elektronik Teknolojisi alanı 4 ortak ders, Motorlu Araçlar Teknolojisi Alanı 6 ortak ders, Yenilenebilir Enerji Teknolojileri Alanı 4 ortak ders, Adalet Alan 19 ortak ders, Gemi yapımı alanı 3 ortak ders, Denizcilik Alanı 5 ortak ders, Çocuk Gelişimi ve Alanı 6 ortak ders, Tesisat Teknolojisi ve İklimlendirme Alanı 5 Ortak Ders, Mobilya ve İç Mekan Tasarımı Alanı 5 ortak ders ve diğer dal dersleridir (Özdemir, 2017, s. 509). Bu bağlamda İHL öğrencilerinin ders çeşitliliği açısından diğer meslek liseli öğrencilere nazaran oldukça yoğun bir program gördükleri ifade edilebilir. 


\section{IMAM HATIP LİSESI ÖĞRENCILERINE GÖRE MESLEK DERSLERİ VE ÖĞRETIMİ}

Öğrenciler için mesleklerin tanıtımında, meslek seçiminde ve mesleğe yönelişte etkili olan faktörlerin başında okullarda verilen meslek dersleri ve öğretimi gelmektedir. Okullardaki eğitim öğretim sürecinde mesleki eğitimini yeterli düzeyde tamamlayan öğrenciler çalışma hayatlarında daha başarılı olmakta ve mesleklerinde daha üretken olmaktadırlar. Bu nedenle meslek dersleri ve öğretimi konusu daha önemli bir hale gelmektedir. Bunun için İHL meslek dersleri öğretmenlerinin alanına hakim olarak bir taraftan MEB'in genel amaçları ve okuldaki derslerin özel amaçlarına uygun davranışları öğrencilere kazandırmaya çalışması gerekmektedir. Diğer taraftan imam hatip meslek dersi öğretmeni, insanın varlığı, yaratılış gayesi, kendisine, ailesine ve yakınlarına, topluma ve yaratanına karşı görev ve sorumluluklarını öğrenmek ve öğretmek olan mesleğe eleman yetiştirecek kişilere, bu bilgileri kazandıracak yeterlilikte olmalıdır (Ev, 2003, s. 32). Yani meslek dersleri ve öğretiminde en önemli rolün öğretmene ait olduğu görülmektedir. Ayrıca mesleğe en iyi bir şekilde eleman yetiştirmek için öğretmenlerin öğrencilere rol model olma konusunda kendilerini yetiştirmenin sorumluğunu taşımaları gerekmektedir. İHL meslek dersleri öğretmenleri meslek ahlakı olarak dürüstlük, güvenilirlik, tutarlılık, örnek olma, mesleğini sevme, insanlara ve toplumun kültür ve değerlerine saygılı olma, özverili olma, insanlarla iyi iletişim kurma, güzel giyinme gibi tutum ve değerlere sahip olmaları gerekmektedir.

Mesleki hayatta özellikle uygulama sürecine haiz alanlarda usta-çırak ilişkisinin varlığ1, kaliteli ve nitelikli eleman yetiştirilmesi için ihtiyacı günden güne hissedilen bir konudur. İHL'lerde mesleki eğitim bünyesinde yer alan meslek derslerinin de bu bağlamda ele alınması gerekmektedir. $\mathrm{Bu}$ nedenle meslek liselerinde uygulanan ve yerinde deneyim yaparak öğrencinin yetişmesine imkan veren staj uygulamasının İHL'lerde de avantajları ve dezavantajları da hesaplanarak daha uzun soluklu olacak şekilde planlanıp uygulanması konusunda çalışmaların yapılması ve politik karar vericiler tarafından gerekli düzenlemelerin yapılmasına ihtiyaç duyulmaktadır.

İmam hatip liseleri ile ilgili araştırmaları dökümantasyon yöntemiyle incelediğimizde öncelikle iki husus karşımıza çıkmaktadır: Bunlar, akademik anlamda başarılı öğrencileri yetiştirmek ve meslek dersleri ve öğretimi konusudur. Ortaöğretim kurumlarında üniversite tercih aşamasındaki aday öğrencilerin büyük oranda meslek tercihleri belirlenmiş durumdadır. Meslek seçimi, kariyer planlaması ve psikososyal memnuniyet açışından yapılan tercih mesleki aidiyet, memnuniyet ve başarı açısından da son derece önemlidir. Onun için meslekî aidiyet, başarı açısından kişinin o mesleğe yönelmeden önce yani daha lisans eğitimine başlarken mesleğinin avantajlı ve dezavantajlı taraflarını, zayıf ve güçlü yönlerini ve toplumdaki statüsünü bilmesi ve tanıması mesleğe başladıktan sonra başarı ve memnuniyet oranını yükseltecektir (Özdemir, 2017, s. 511).

İHL'lerde meslek dersleri ve öğretimi ile ilgili yapılan yakın tarihli araştırmalara bakıldığında; Karaman (2021) tarafindan Türkiye geneli 35 İHL ve 4802 öğrencinin görüşlerini kapsayan araştırmada İHL öğrencilerinin meslek derslerine ve öğretimine ilişkin görüşlerinde farklılıkların olduğu ifade edilmektedir. Bu bağlamda İHL öğrencilerinin \%55,7'si meslek derslerini verimli bulmadığını, \%37,8'i meslek derslerinin ilgisini çekmediğini, \%39,4'ü meslek derslerinin işleniş yönteminin derslere ilgisini azalttığını, \%74,1'i meslek derslerinin daha ilgi çekici hale getirilmesi gerektiğini ve \%62,4'ü ise müfredatta meslek derslerine daha fazla yer ayrılmaması gerektiğini belirtikleri görülmektedir (Karaman, 2021, s. 152).

Kaya'nın (2018) araştırmasında sadece ilahiyat eğitimi almak istemeyen öğrencilerin değil genel olarak tüm imam hatip lisesi öğrencilerinin meslek dersleri ile ilgili benzer olumsuz kanaatlere sahip olduğu, meslek derslerinin 12. sınıfta çok fazla olduğu ve 9. ve 10. sınıfta meslek derslerinin sayısının fazla olabileceği ancak 11 ve 12. sınıfta azaltılması gerektiği ifade edilmektedir (Kaya, 2018, s. 76). Korkmaz'ın (2013) araştırmasında öğrenciler; özellikle meslek derslerinin zorluğundan, ezberlerin çok oluşundan, kendilerinin bu derslere uyum sağlayamamasından dolayı imam hatip 
lisesinde okumaktan memnun olmadiklarını ifade etmektedirler (Korkmaz, 2013, s. 28). Kula'nın (2013) araştırmasında da, İHL'ye istemeden gelen öğrenciler meslek derslerinin zor olduğunu düşünmektedir (Kula, 2013, s. 604). Mücahit (2017) meslek derslerinin zorunlu olmayıp seçimli olması durumunda yaklaşık \%40 oranındaki bir öğrencinin bu dersleri seçmeyeceğini belirttiklerini ifade etmektedir. (Mücahit, 2017, s. 97). Karateke'nin (2015) çalışmasında ise; özellikle 12. sınıftaki meslek derslerinin, öğrencilerin üniversite sınavına çalışmak için rapor almaları ve üniversite sınavinda bu derslerden soru sorulmaması sebebiyle, önemsenmeyen dersler olduğu vurgulanmaktadır (Karateke, 2015, 167). Meslek dersleri ile ilgili benzer durumlar Tük-Eğitim-Sen tarafından düzenlenen "Din Eğitimi Çalıştayı”nda da ifade edilmekte, ayrıca bu durumun öğretmen ve öğrenciler arasında probleme yol açtığ 1 da eklenmektedir (Türk Eğitim-Sen, 2015, s. 46). Çakır ve diğerlerinin (2004) araştırmasında yer alan bir imam hatip mezununun "Mezun olduğumda kendimi yeterli görmüyordum. Çünkü üniversiteye yönelmiştik. Meslek dersleriyle uğraşmaktan çok fen bilgisi, matematik, geometri, Türkçe ve tarih çalışıyorduk." şeklindeki ifadesi de bu derslerin üniversite sınavının gerisinde, ikinci planda kalan dersler olduğunu göstermektedir (Çakır vd., 2004, s. 120).

Aşlamacı'nın (2017) araştırmasında öğrencilerin \%80,8'i meslek derslerinin daha ilgi çekici hale getirilmesi gerektiğini, öğrencilerin üçte birinin $(\% 33,5)$ meslek derslerini sıkıcı bulduğunu, dörtte birinin $(\% 25,7)$ meslek derslerinde işlenen konuların ilgisini çekmediğini ifade etmekte, yaklaşık yarısının $(\% 48,4)$ meslek derslerinin işleniş yönteminin derslere ilgisini azalttığını belirtmekte, yine öğrencilerin yaklaşık yarısı $(\% 45,9)$ İHL programında meslek derslerinin oranının artırılmasına karşı çıkmakta ve \%51,2'si meslek derslerinde birbirini tekrar eden konuların işlendiğini dile getirmektedir (Aşlamac1, 2017, s. 57-62).

Yukarıda ifade edilen araştırma sonuçları, meslek derslerinin niteliğiyle ilgili olarak çeşitli sorunların olduğu şeklinde yorumlanabilir. Ayrıca tüm araştırma sonuçları, özellikle meslek derslerinin içeriği ve öğretim sürecinin, önemli orandaki AİHL öğrencisinin ilgi, ihtiyaç ve beklentilerine yeterince hitap etmediğini göstermektedir. $\mathrm{Bu}$ nedenle özellikle meslek dersleri müfredatı ve öğretim süreci AİHL öğrencilerinin gelişim özelliklerine ve onların ilgi, gereksinim ve beklentilerine hitap edecek tarzda yeniden gözden geçirilmelidir. Ayrıca öğrencilerin dünyadaki teknolojik gelişmeleri takip etmesi, öğrencilerle teknolojik gelişmelerle ilgili dijital dönüşümün gerisinde kalan bazı meslek dersi ögretmenleri arasında sağlıklı iletişimin sağlanamaması da meslek derslerine olan ilgiyi olumsuz anlamda etkilemektedir. Bunun için Milli Eğitim Bakanlığı tarafından kurulan Eğitim Bilişim A ̆ğı'nda (EBA) ve Din Öğretimi Genel Müdürlüğü tarafından kurulan kurumsal web sitelerinde IHL meslek dersleri ile ilgili çalışmaların, etkinliklerin tamamlanmış olması, çalışmaların süreç içerisinde gelişmeler ışığında güncellenmesi önem arz etmektedir. Ayrıca meslek dersleri öğretmenlerinin özellikle etkileşimli tahtaların etkin olarak kullanılması ile derslerini öğrencilerin ilgisini çekecek tarzda işlemeleri gerekmektedir.

Buna ilaveten İHL öğrencilerinin büyük çoğunluğunun gelecekle ile ilgili hedeflerinin meslek yerine üniversite yönelimli olmasının, üniversite yerleştirme sisteminde ise ortak derslerden sorular sorulup meslek derslerinden soru çıkmamasının sonucu olarak öğrencilerin meslek derslerini önemsemedikleri ifade edilebilir. Ayrıca İHL müfredatında meslek derslerinin son sınıflarda yoğunlaşması, bu yılların ise öğrenciler tarafından üniversite sınavlarına hazırlık yılları olması bir sorun olarak ifade edilmektedir. (Türk Eğitim-Sen, 2015, s. 46). Bu sorunlara ilişkin olarak Aşlamacı'nın araştırmasında elde edilen verilere bakıldığında İHL öğrencilerinin \%43,3’ü lise 1 ve 2. sınıflarda meslek derslerine daha fazla yer verilmesini istemektedir. Ayrıca araştırma sonuçları, öğrencilerin \%52,9'unun İlahiyat fakültelerinde öğrenim görmek için üniversite giriş sınavlarında meslek derslerinden de soru sorulmasını talep ettiklerini ortaya koymaktadır. Araştırmada ulaşılan diğer bir sonuca göre meslek dersleri öğretmenlerinin yaklaşık üçte ikisi $(\% 65,8)$ İHL öğrencilerinin meslek derslerine karşı ilgilerini yetersiz bulmaktadır (Aşlamacı, 2017, s. 156-157). 
Cebeci'nin araştırmasına katılan meslek dersleri öğretmenlerinin \%34,8'i bazı öğrencilerin derslere ilgili ve aktif olarak katıldığını, \%30,6'sı çoğu öğrencinin derslere ilgili ve aktif olarak katıldığını, \%15,3'ü çok az öğrencinin derslere ilgili ve aktif olarak katıldığını belirtirken, öğretmenlerin sadece \%11'i öğrencilerin genelde hepsinin derslere ilgili ve aktif olduğunu ifade etmektedir (Cebeci, 1994, s. 96). Bu veriler birlikte değerlendirildiğinde öğrencilerin meslek derslerine karşı ilgilerinde zaman içerisinde önemli bir değişimin yaşanmadığı kolaylıkla ifade edilebilir.

\section{SONUÇ}

Öğretme ve öğrenme faaliyetleri tüm zaman ve mekanlarda farklı biçim ve anlayışlarla varlığını sürdürmüştür. Bu faaliyetler esnasında çoğunlukla öğrenciler, öğretmenler ve öğretim programları üzerine çokça araştırmalar yapılmıştır. İmam hatip okulları üzerine yapılan araştırmaların kapsamı da aynı konularda yoğunlaşmıştır. Bu durum bize eğitim öğretim sürecinde odaklanmamız gereken alanı göstermesi açısından önemlidir. İmam hatip liselerinde akademik başarı için kültür dersleri öğretmenlerinin üstlendiği görev sorumluğu ve çalışmaları ile bağlantılı olarak öğrencilerin üniversite sınavlarındaki başarıları ortaya çıkmaktadır. Bu durum öğrencilerin mesleki eğitiminin yeterli olmasında meslek dersleri öğretmenlerinin rol modelliğinin nasıl ve ne düzeyde olması gerektiğini bize göstermektedir. Yani tüm eğitim kurumlarında öğrenci merkezlilik esas olmakla birlikte öğretmenlerin bir orkestra şefi gibi hareket etmeleri gerekmektedir. edebiliriz:

Araştırmalarda meslek dersleri ve öğretimi ile ilgili öne çıkan sonuçları ise şu şekilde ifade

- $\quad$ İHL öğrencileri meslek derslerini verimli bulmamaktadır.

- Meslek dersleri öğrencilerin ilgisini yeterince çekmemektedir.

- Meslek derslerinin işleniş yöntemi öğrencilerin derslere olan ilgisini azaltmaktadır.

- Meslek derslerinin daha ilgi çekici hale getirilmesi gerekmektedir.

- $\quad$ İHL'de meslek derslerinin sayısı oldukça fazladır ve müfredatta meslek derslerine daha fazla yer ayrilmamalidir.

- Üniversite sınavlarında meslek derslerinden soru çıkmaması meslek derslerine olan ilgiyi azaltmaktadir.

- İHL'lerde meslek dersleri 11. ve 12. sinıfların yerine 9. ve 10. sinıfta daha yoğun olarak verilmelidir.

- Bugün itibariyle proje imam hatip liselerinde meslek derslerinin tüm dersler içerisindeki oranı $\% 25$ 'tir. Bu oran diğer AİHL'lerde ise \%30' civarındadır. Bu oranlar meslek derslerinin diğer dersler içerisindeki ağırlığ noktasında gelinen son durumu göstermektedir. Bu durum bir taraftan akademik başarı beklentisinde olan öğrenci ve velilerin görüşlerini; diğer taraftan İHL öğrencilerinin mesleki yeterlilik düzeylerine yapacağı etkinin araştırmalarla bilimsel olarak ifade edilmesi gerekmektedir.

\section{4. ÖNERILER}

Tebliğimizde açıklamaya çalıştığımız, sonuçta da özetlemiş olduğumuz hususların çözümüyle ilgili aşağıdaki önerilerin dikkate alınmasının sorunun çözümüne katkısının olacağı kanaatini taşıdığımızı belirtmek yerinde olacaktır.

- İmam hatip meslek dersleri ve öğretimi konusunda meslek dersleri öğretmenlerinin rol modelliği öne çıkmaktadır. Öğretmenlerin nitelikli ve mesleki alan bilgisine sahip olarak 
teknolojiyi kullanabilen ve iletişimi güçlü olan öğretmenler olmaları gerekmektedir. $\mathrm{Bu}$ anlamda İHL meslek dersleri öğretmenliği İlahiyat Fakültesinde ayrı bir program olarak yer almalı ve program istihdam alanının özellikleri dikkate alınarak yapılandırılmalıdır.

- İmam hatip meslek dersleri öğretmen adaylarının Pedagojik Formasyon eğitimleri İlahiyat Fakültesi içinde ve özellikle de "Öğretmenlik Uygulamalarıyla ilgili dersler alan eğitimciler tarafından verilmelidir. Ayrıca Formasyon eğitim süreci daha uzun soluklu planlanmalıdır.

- $\quad$ Alanında uzmanlaşması için imam hatip meslek dersleri öğretmenlerinin ders çeşitliliği azaltılmalı ve öğretmenler için alan bilgisini arttıracak hizmet içi eğitimlerin verilmesi gerekmektedir.

- $\quad$ Proje AİHL'lere ve meslek derslerine olan ilgiyi arttırmak için ÖSYM tarafından yapılan sınavlarda meslek derslerinden soru sorulması sağlanabilir. Ayrıca öğrencilerin mesleki yarışmalarda elde ettikleri derecelerin karşılığı mesleki derslere olan ilgiyi artırması bağlamında üniversiteye yerleşmede ek puan olarak verilmesi sağlanabilir.

\section{KAYNAKÇA}

[1] Aşlamacı, İ. (2017). Öğrenci ve öğretmenlerine göre imam-hatip liseleri: profiller, algılar, memnuniyet, aidiyet, Dem Yayınları, İstanbul.

[2] Cebeci, S. (1994). İmam hatip lisesi meslek dersleri öğretmenlerinin yeterlilikleri, (Doktora Tezi), Ankara Üniversitesi Sosyal Bilimler Enstitüsü, Ankara.

[3] Çakır, R. \& Bozan, İ. \& Talu, B. (2004). İmam hatip liseleri efsaneler ve gerçekler, Tesev Yayınları, İstanbul.

[4] Ev, H. (2003). Türkiye'de yüksek din öğretimi kurumları ve öğretmen yetiştirme, Tibyan Yayıncılık, İzmir.

[5] Karaman, D. (2021). İmam hatip liselerinde program çeşitliliği ve proje okul uygulamaları. (Doktora Tezi). Sakarya Üniversitesi Sosyal Bilimler Enstitüsü, Sakarya.

[6] Karateke, T. (2015). İmam hatip liselerinde idarecilerin karşılaştıkları sorunlara yönelik nitel bir çalı̧̧ma. Amasya Üniversitesi İlahiyat Fakültesi Dergisi 3 (5), 145-171. Doi: 10.18498/amauifd.51200.

[7] Kaya, Z. (2018). İlahiyat dışında lisans eğitimi planlayan imam-hatip lisesi öğrencilerinin meslek dersleri ile ilgili değerlendirmeleri üzerine nitel bir araştırma. İslam Medeniyeti Araştırmaları Dergisi (IMAD) (The Journal of Islamic Civilization Studies) 3 (1), 61-96.

[8] Korkmaz, M. (2013). İmam hatip lisesi öğrencilerinin bu okulu tercih süreçleri. Erciyes Üniversitesi İlahiyat Fakültesi Dergisi 16, 7-40.

[9] Kula, T. (2013). Diyarbakır'da bulunan imam hatip lisesinde okumakta olan öğrencilerin hedef yönelimleri nelerdir?, R. Kaymakcan (Ed.), 100. Yılında İmam Hatip Liseleri Sempozyumu (65-104) içinde. İstanbul: Dem Yayınları.

[10] Milli Eğitim Bakanlığı, (2018). Ortaöğretim kurumları haftalık ders çizelgesi, PDF: Talim Terbiye Kurulu Başkanlığ1, https://ttkb.meb.gov.tr/meb_iys_dosyalar/2018_02/21173451_ort_ogrtm_hdc_2018.pdf

[11] Milli Eğitim Bakanlığı. (2020). Milli eğitim istatistikleri örgün eğitim 2019-2020, PDF: Strateji Geliştirme

Başkanlığg1, http://sgb.meb.gov.tr/meb_iys_dosyalar/2021_09/10141326_meb_istatistikleri_orgun_egitim_2020_2021.pd $\mathrm{f}$

[12] Mücahit, M. (2017). Öğrencilerin gözüyle imam hatip lisesi meslek dersleri öğretmenleri (Sivas ili örneği). Cumhuriyet Üniversitesi Fen-Edebiyat Fakültesi Sosyal Bilimler Dergisi 41 (1), 73-99.

[13] Özdemir, S. (2017). İmam hatip meslek dersi öğretmenlerinin diğer meslek dersleri öğretmenleriyle karşılaştırılması. İ. Erdem vd. (Ed.), Geleceğin İnşasında İmam Hatip Okulları I (503-516) içinde. Malatya: İnönü Üniversitesi Yayınevi.

[14] Zengin, M. (2017). Modern Türkiye'de din ve eğitim politikaları ekseninde İmam Hatip Okulları üzerine bir analiz. İ. Erdem vd. (Ed.), Geleceğin İnşasında İmam Hatip Okulları I (41-55) içinde. Malatya: İnönü Üniversitesi Yayınevi. 